\title{
Strength and Efficiency during Lap Joining Molding of GMT-sheet
}

\author{
Jin-Woo Kim1, Hyoung-Seok Kim1, Tae-Ik Kim², Dong-Gi Lee1, and Jae-Ki Sim1 \\ 1 Department of Mechatronics Engineering, Chosun University, 375 Seosuk-dong, Gwang-ju 501-750, Korea \\ 2 Department of Advanced Parts and Materials Engineering, Chosun University Graduate School, 375 Seosuk-dong, Gwang-ju 501-750, Korea \\ \# Corresponding Author / E-mail: jgsim@chosun.ac.kr, TEL: +82-62-230-7011, FAX: +82-62-233-7905 \\ (Manuscript received: Nov, 2, 2012 / Revised: Dec, 4, 2012 / Accepted: Dec, 5, 2012)
}

\begin{abstract}
In order to substitute and recycle the existing automobile parts for GMT-sheet, researches on the effects of GMT-sheet on the establishment of precise joining strength, joining condition that are lap length of joining part, compression ratio, and closure speed must be carried out but until now. Besides, many researches on adhesion joint had been conducted until now but no systematic research on press lap joint of GMT-sheet has been implemented until recently and the reliability of joining strength is not yet established. In press lap joining molding of GMT-sheet, tensile stress and lap joining connection efficiency was increased according to the increase of lap length L. However, as the increase of compression ratio and fiber content ratio per unit area was higher in tensile test, it has caused the deterioration of lap joining efficiency after joining molding of GMT-sheet. Clarify joining strength and lap joining efficiency during high temperature compression press lap joining molding of GMT-sheet and research data regarding to the lap length of joining part was presented. The purpose of this study is to contribute to the substitution of existing products as well as usage development in non-automobile field and also to find out precise dynamic characteristics as designing data of structures.
\end{abstract}

KEYWORDS: GMT-sheet, Joining efficiency, Compression ratio, Lap joint, Closure speed

\section{Introduction}

For glass mat reinforced thermoplastic sheet (Hereinafter called as the GMT-sheet), UD grade (unidirectional grade), which is built up of random glass fiber mat and unidirectional oriented straight fiber, is developed and being used. In particular, GMT-sheet that is manufactured in combination of minerals and organic matter not only approach almost near to the strength of thermosetting composite but also has excellent productivity, recycling, and impact resistance, which are pointed as weaknesses of thermosetting composites. And as it also has many advantages such as molding, strength, hardness, anti-medicines resistance, relatively cheap price, excellent strength and tensile strength/tension and as it has thermoplastic as its matrix, it is now composite material that attracts most attention in the aspect of recycling ${ }^{(1 \sim 3)}$. As the scope of use as parts of automobiles using the characteristics of GMT-sheet has is increasing and as the scope of use for other than automobiles is also expanding, the issue of joining of GMT-sheet is required to be solved in advance for more broad use. Stress reduction effect is only partial in case non-adhesion part of steel is partially tilted by conducting the analysis of cylinder adhesion joint consisted of composite and steel tube under twisted load. It had researched to the effect of delivery capacity of static torque of cylinder single lap adhesion joint with steel-steel non-adhesion part on the adhesion thickness. It had been examined that torque transmission capacity is reduced according to the increase of the adhesion thickness. It had been conducted adhesion strength test of a simple lap joint of aluminum alloy and had been evaluated the characteristics of adhesion strength by suggesting joining coefficient that has considered lap length, thickness of adhesive matter, and thickness of adhesion layer. In this study, materials with each different fiber content ratio and fiber orientation state were used in the study for decision of molding condition of GMT-sheet and the condition of lap joining ${ }^{(4 \sim 7)}$.

\section{Theory}

Compression ratio $R_{c r}$ is defined as Eq. (1) in case of compressing the initial thickness ho to $\mathrm{h}$ in only length direction by deploying specimen in Fig. 1 during high temperature \& compression press joining molding and by binding the flow of materials in width direction in Fig. 2.

$$
R_{c r}=1-\frac{h}{h_{0}}
$$

where, $h$ is thickness after molding, and $h_{0}$ is thickness before molding.

Calculation equation of average vertical stress that applies to 
section of specimen is Eq. (2) and the number of test was conducted in each 5 times respectively and was calculated in average value ${ }^{(8)}$.

$$
\sigma_{(t, c)}=\frac{P_{(t, c)}}{b \cdot t}
$$

where, $\sigma_{(t, c)}$ is maximum vertical stress (MPa), $P_{(t, c)}$ is maximum load $(\mathrm{N}), b$ is width of specimen $(\mathrm{m}), t$ is thickness of specimen $(\mathrm{m})$, and $t$, $c$ is tensile, compression.

Liquid-solid multiphase flow with fiber as solid and matrix as liquid during high temperature \& compression press molding is generating separation by the difference of flow speed the as the molding is progressing and the molding products become heterogeneous. As shown in Fig. 2, combustion specimens for measuring the degree of heterogeneity of molding products after compression molding are extracted at each $10 \mathrm{~mm} \times 10 \mathrm{~mm}$ respectively along the $x$ axis in the neutral surface of the molding
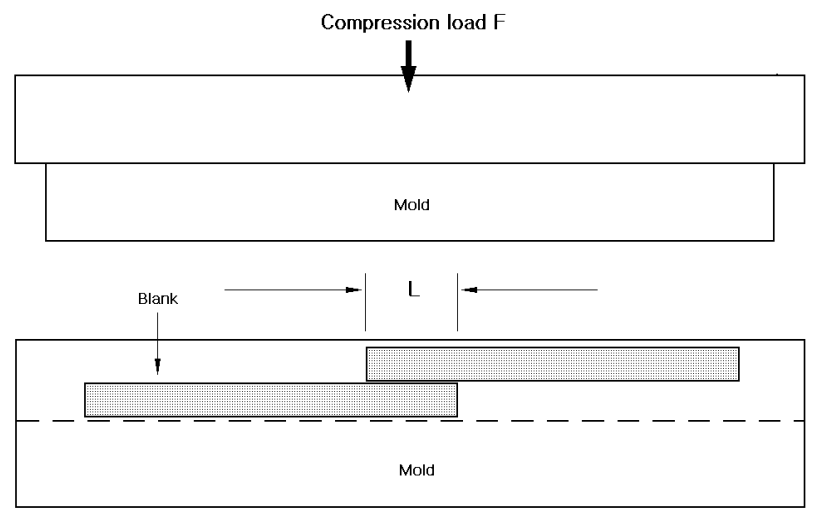

Fig. 1 Illustration of GMT-sheet joining process
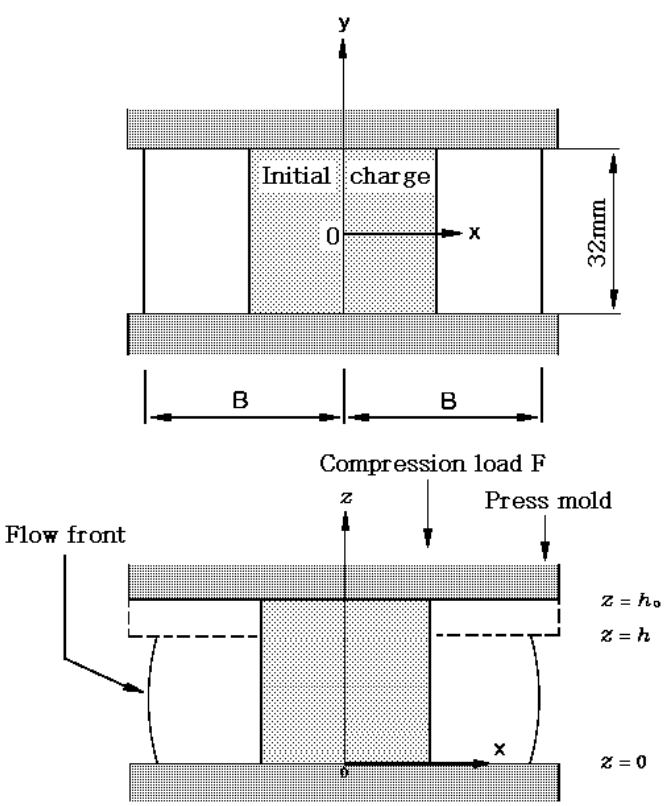

Fig. 2 Nomenclature for slab-shaped part compression molding

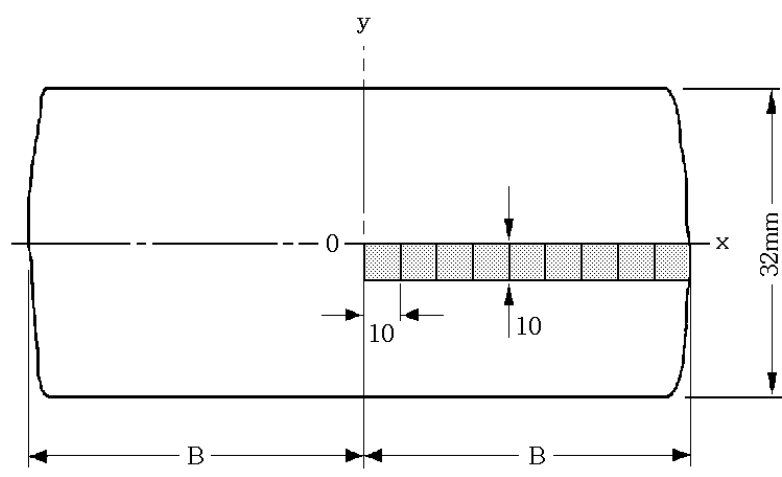

Fig. 3 Parts for measuring fiber content by means of burning

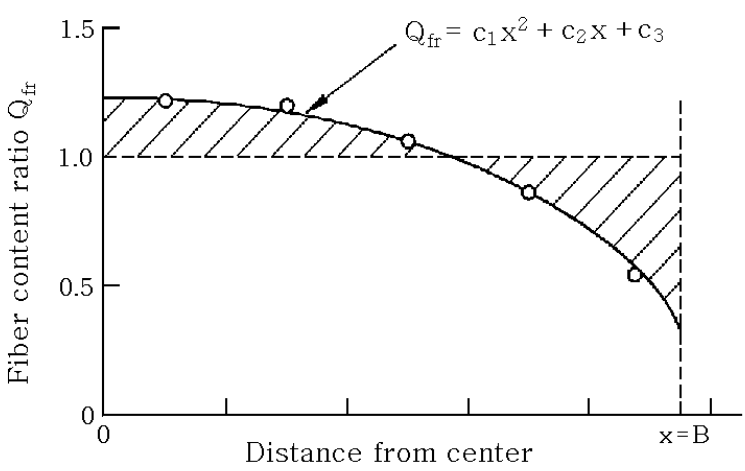

Fig. 4 Distribution of the fiber content ratio

products in Fig. 3. And it was heat and burn specimens at $600{ }^{\circ} \mathrm{C}$ for 30 minutes using an electrical furnace and measured fiber contents ratio in the weight before and after burning using precision electronic scale $(1 / 10,000 \mathrm{~g})$. Thus, the distribution of fiber content ratio is depicted in Fig. 4 after calculating fiber content ratio $Q_{f r}$ in the Eq. (3).

$$
Q_{f r}=\frac{q_{f}}{q_{f_{0}}}
$$

where $q_{f}$ is weight fiber content ratio after molding, and $q_{f 0}$ is weight fiber content ratio before molding.

Lap joining connection efficiency $(\eta)$ by the test strength value of GMT-sheet molding products during high temperature \& compression press molding is calculated from Eq. (4).

$$
\eta=\frac{\text { Molding strength after joining connection }}{\text { Molding strength before joining connection }}
$$

Molding products become heterogeneous as they become more separated and the relationship between fiber content ratio and fluidity distance be expressed in quadratic function is shown in Fig. 4. Molding products become heterogeneous by having larger area of diagonal line as they become more separated. The distribution curve of fiber content ratio $Q_{f r}$ as quadratic function is calculated, 
coefficient $C_{1}, C_{2}$, and $C_{3}$ are obtained using method of least square. Afterward the degree of heterogeneity $\Gamma$ of molding products was depicted by calculating the area of diagonal line. It is calculated from Eq. (5).

$$
\Gamma=\frac{\text { Area of diagonal }}{B \times 1}
$$

where, $\Gamma$ is dimensionless number and exists between 0 and 1 but if it is near to 0 , molding products become more homogeneous.

\subsection{Molding condition}

Materials are products of Azdel company of the USA and randomly oriented composite (matrix: polypropylene, reinforcement: random glass mat, hereinafter called as R2038, R3038, and R4038) with fiber content ratio of each $20 \mathrm{wt} \%, 30 \mathrm{wt} \%$, and $40 \mathrm{wt} \%$ respectively was used by reinforcing with the thickness ho of $3.8 \mathrm{~mm}$ and unidirectionally oriented composite (matrix: polypropylene, reinforcement: unidirectional glass mat, hereinafter called as the U4038, U4238, and U5038) with fiber content ratio of each $40 \mathrm{wt} \%, 42 \mathrm{wt} \%$, and $50 \mathrm{wt} \%$ respectively was used by reinforcing after unidirectionally oriented straight line fiber. Density of fiber and plastic is each $2.55 \mathrm{~g} / \mathrm{cm}^{3}$ and $0.9 \mathrm{~g} / \mathrm{cm}^{3}$ respectively. After GMT-sheet were cut into rectangle sheet in the size of $32 \mathrm{~mm}$ (width) $\times 100 \mathrm{~mm}$ (length) $\times 3.8 \mathrm{~mm}$ (thickness) using a diamond cutter, these specimens were compression molded after charging the blank in metal mold by heating in an electrical oven (200 ${ }^{\circ} \mathrm{C}$ ) for heating for about 30 minutes. The dimension of metal mold cavity was $32 \mathrm{~mm} \times 300 \mathrm{~mm}$ and 25 tons hydraulic thermo press (Carver, model: 2518) was used. Metal mold was attached and thermocouple, rod, and plate heater were used for heating.

In order to examine the relationship between compression ratio, compression load, and degree of heterogeneity according to compression speed during high temperature \& compression press molding, compression speed of press was set at 4 kinds of 0.1 $\mathrm{mm} / \mathrm{min}, 1 \mathrm{~mm} / \mathrm{min}, 10 \mathrm{~mm} / \mathrm{min}$, and $100 \mathrm{~mm} / \mathrm{min}$ and it was compression molded by changing compression ratio per each compression speed respectively. Load value was obtained according to each molding condition by using $\mathrm{x}-\mathrm{y}$ recorder during compression molding. Thickness of compressed specimen was obtained by attaching a dial gauge. Mechanical property of GMT-sheet before and

Table 1 Mechanical properties of R4038 and U4238

\begin{tabular}{|c|c|c|c|}
\hline Specimen & Unit & $\mathrm{R} 4038$ & $\mathrm{U} 4238$ \\
\hline Glass fiber content & $\mathrm{wt} \%$ & 40 & 42 \\
\hline \multirow{2}{*}{ Tensile strength } & $\mathrm{MPa}$ & $* 88$ & $* 93$ \\
& & $* * 80$ & $* * 84$ \\
\hline \multirow{2}{*}{ Compressive strength } & $\mathrm{MPa}$ & $* 86$ & $* 91$ \\
& & $* 79$ & $* * 85$ \\
\hline
\end{tabular}

* Virgin (Before molding) ** Recycled (After molding) after molding is depicted in Table 1 and unidirectional oriented composite U4238 with unidirectional glass fiber had larger value of tensile strength and compression strength than randomly oriented composite R4038. Values in Table 1 are strength values in order to estimate lap joining connection efficiency and values of strength after molding showed about $10 \%$ lower than the values before molding. Here, $*$ is value of strength of specimen before molding, ** is the value of strength after molding and at this time, blank and metal mold temperature was set in the same at $200{ }^{\circ} \mathrm{C}$ with compression ratio at 0 , and press compression speed was set at $100 \mathrm{~mm} / \mathrm{min}$ in molding conditions.

\subsection{Lap joining molding and strength test}

As thermoplastic is melting as the temperature increases, it is joined by fusion welding at low temperature. Fusion welding is useful in joining fiber reinforced plastic composites that are not joined with adhesive materials. Lap length $L$ for GMT-sheet with the thickness $t$ $(3.8 \mathrm{~mm})$ before high temperature $\&$ compression press lap joining molding was set in 5 kinds of $\mathrm{t} 1, \mathrm{t} 3, \mathrm{t} 5, \mathrm{t} 7$, and $\mathrm{t} 9$. In order to measure joining strength of lap joining parts, tensile tests were carried out. At this time, fracture strength of specimens was set at the value of dividing fracture load by sectional area of specimen (width $\times$ thickness) and the tests were carried out 5 times per each test condition and their average value was taken.

Tensile test was set at $25.4 \mathrm{~mm}$ (width) $\times 152.4 \mathrm{~mm}$ (length) by considering ASTM D638 standards and it was manufactured with gauge length of $76.2 \mathrm{~mm}$. Cross head speed of material test machine ( 5 ton, British, Hounds-Field) was set at $1 \mathrm{~mm} / \mathrm{min}$. X-ray generation device for filming soft X-ray was HF-46 (mammography) of Japanese Akoma and film used was the products of Japanese Fuji films (MI-NC X-ray film for medical purpose, $180 \mathrm{~mm} \times 240 \mathrm{~mm}$ ).

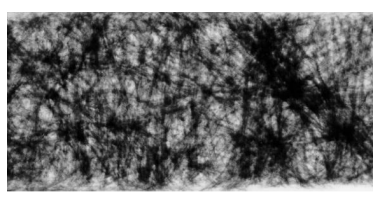

(a) GMT-sheet R4038

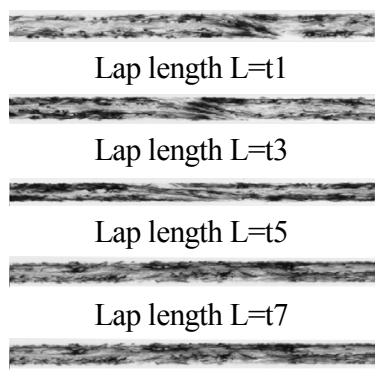

Lap length $\mathrm{L}=\mathrm{t} 9$

(c) GMT-sheet R4038

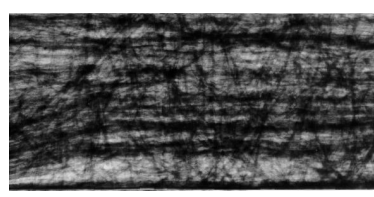

(b) GMT-sheet U4238

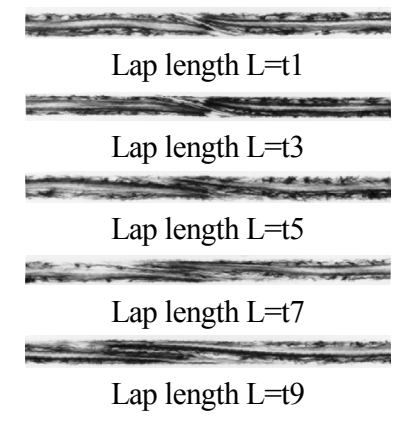

(d) GMT-sheet U4238
Fig. 5 Soft X-ray photograph of GMT-sheet 
In Fig. 5(a), when lap joining molding, fiber of randomly oriented composite has oriented in the flow direction when fiber was flown as disposition of original fiber was arranged randomly. However, as fiber of unidirectional oriented composite is oriented in Fig. 5(b), the separation between matrix and fiber was not only generated severely but also glass fiber was sheared by high compression pressure of press since glass fiber was sheared without being flown into the direction of length and consequently, the nature of joining was poor.

Fig. 5(c) and (d) shows the soft X-ray of filming side part of lap joining molding materials of GMT-sheet (R4038, U4238) and from these figures, joining was worked good as joining boundary surface was bigger as lap length was increased. From $t 1$ to $t 5$ of lap length, boundary surfaces of joining surfaces were appeared but for over $\mathrm{t} 7$ of lap length, glass fiber was well joined with matrix at joining surfaces. In this figure, R4038 GMT-sheet showed better joining nature than U4238.

\section{Test Results and Discussion}

Fig. 6 shows the SEM filming of fracture surface by testing tensile of lap joining part (R4038, $40 \mathrm{wt} \%, \mathrm{~L}=\mathrm{t5}$ ) in Fig. 5. It was observed that fracture was generated in the cross-section as slope cross-section was generated in left and right side of this figure during joining. When high temperature \& compression molding GMT-sheet, flow between layers of fibers that are side by side between layers was generated. It was noticed that phenomena of fractures were not transmitted between one layer but the fractures were transmitted to adjacent other layers or expanded to several layers by bridging phenomenon of fiber when fractures were transmitted.

Fig. 7 shows the relationship between compression ratio and press compression load according to compression speed for examining molding conditions of GMT-sheet (R4038, $40 \mathrm{wt} \%$ ). Compression load of press was increased as the more compression ratio increased and compression load was also increased as the compression speed becomes faster. Because solid part (glass fiber) is more than liquid

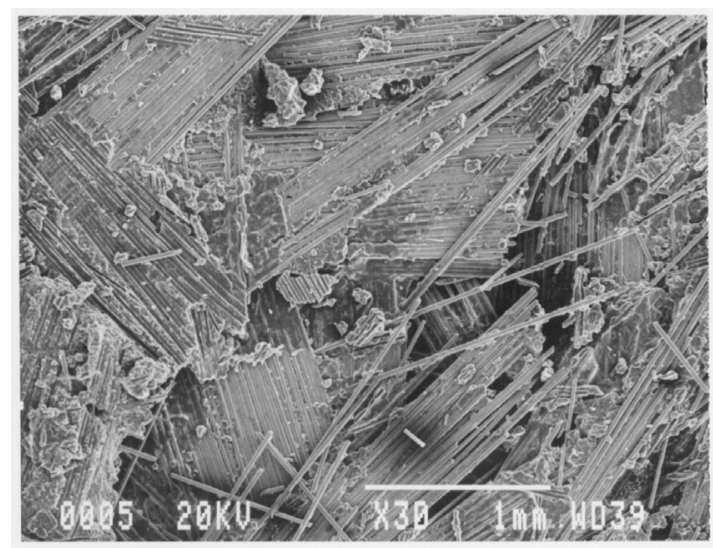

Fig. 6 Fractured surface of GMT-sheet R4038 part (polypropylene) during fluidity molding as the quantity of fiber within composites is larger and it requires more necessary strength in moving things as the compression speed is more faster.

Fig. 8 shows the relationship between compression ratio $R_{c r}$ and degree of heterogeneity $\Gamma$ according to the changes of compression speed for measuring degree of heterogeneity of GMT-sheet (R4038, $40 \mathrm{wt} \%$ ). Degree of heterogeneity of molding products appearance becomes larger since the separation of fiber and matrix becomes larger as the structure of mat of glass fiber is tangled strong in each other as the compression ratio is increasing and also as the degree of heterogeneity appears larger, the more compression speed is smaller as matrix flow only. The distribution of fiber content ratio of molding

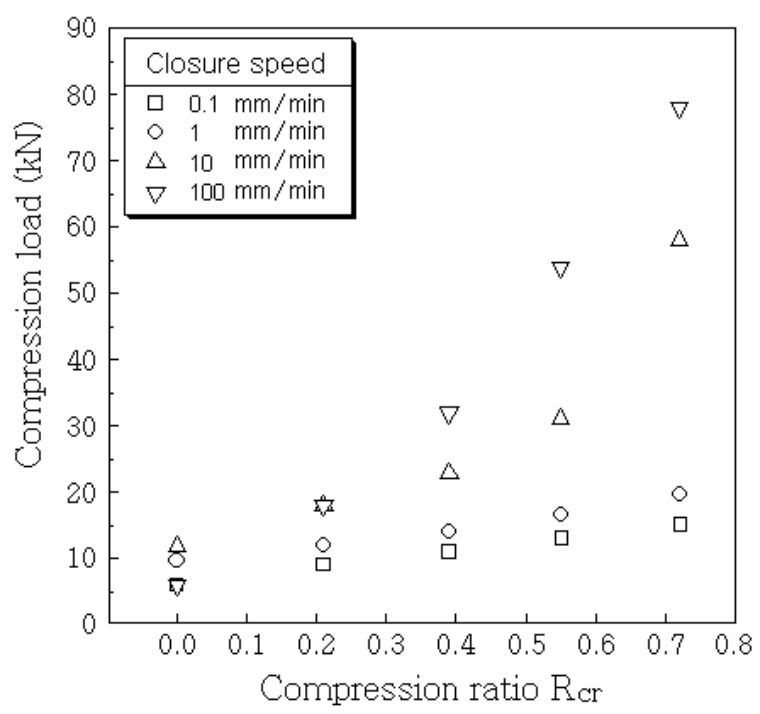

Fig. 7 Relationship between compression ratio $R_{c r}$ and compression load $F$

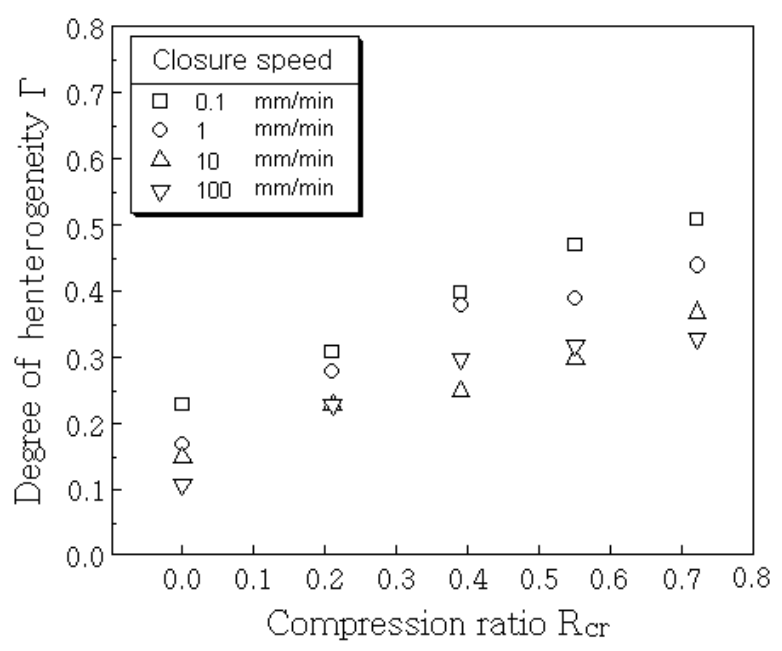

Fig. 8 Relationship between compression ratio $R_{c r}$ and degree of heterogeneity $\Gamma$ 
products is changes as separation is generated by the difference of flow speed of matrix and reinforcing materials.

Fig. 9 shows the lap joining connection efficiency according to the changes of lap length by testing tensile after lap joining molding in the condition that compression ratio $\left(R_{c r}\right)$ is set at 0 . By compared values of strength of molding material obtained by testing tensile only after high temperature compression press molding in a state of non-overlapping of GMT-sheet and values of strength of joining materials obtained by lap joining molding, and joining connection efficiency according to lap length was compared. Lap joining efficiency was increased as lap length $L$ was increased in Fig. 9 (a) and (b).

As shown in Fig. 9(a), lap joining connection efficiency of randomly oriented composite R2038, R3038, and R4038 appeared almost similar and in Fig. 9 (b), joining connection efficiency of

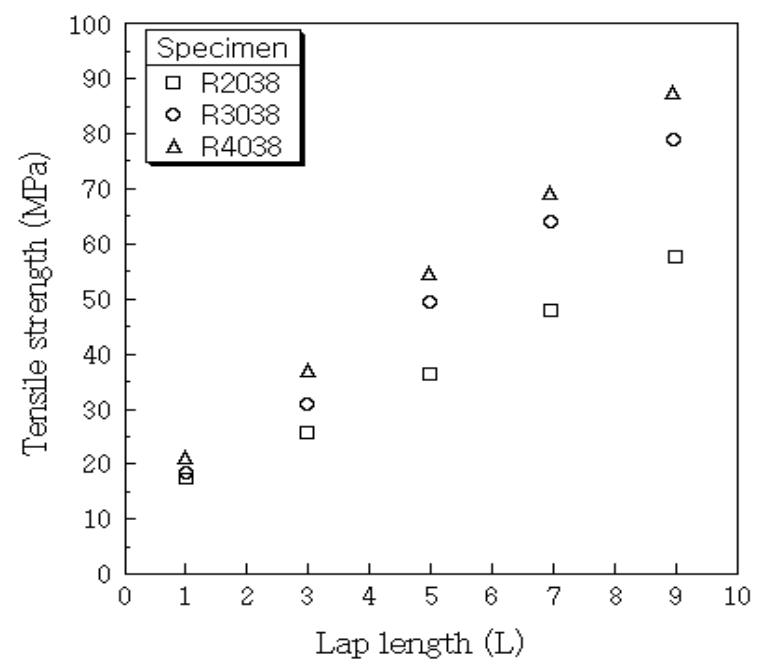

(a) Random GMT-sheet

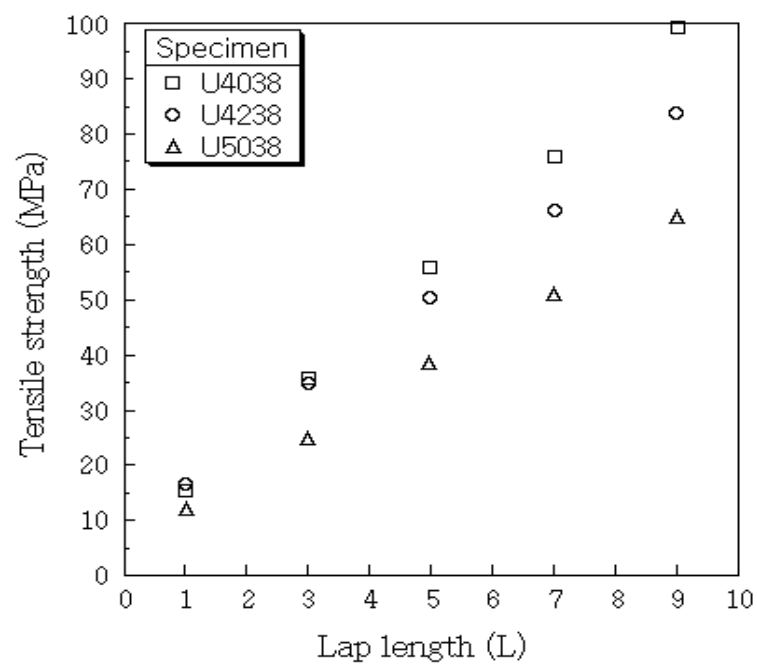

(b) Unidirectional GMT-sheet

Fig. 9 Effects of joining efficiency on the lap length $L$ unidirectional oriented composite U4038, U4238, and U5038 was reduced as fiber content ratio was higher. As shown in Fig. 9 (b), as fiber content ratio was lower, joining efficiency appeared higher as melting fusion of matrix that played the role of adhesive materials was good and randomly oriented composite showed higher lap joining connection efficiency than unidirectional oriented composites.

Because fiber of randomly oriented composite is flown in the direction of length during molding but fiber of unidirectional oriented composites is sheared a lot in addition to becoming separation of only resins of matrix by the fluidity due to high compression pressure of press without orientation of fiber as fiber is layed in the direction of fluidity.

Strength and joining connection efficiency of molding products were increasing according to the increase of lap length. Because glass fiber as reinforcement is not melted during lap joining molding and

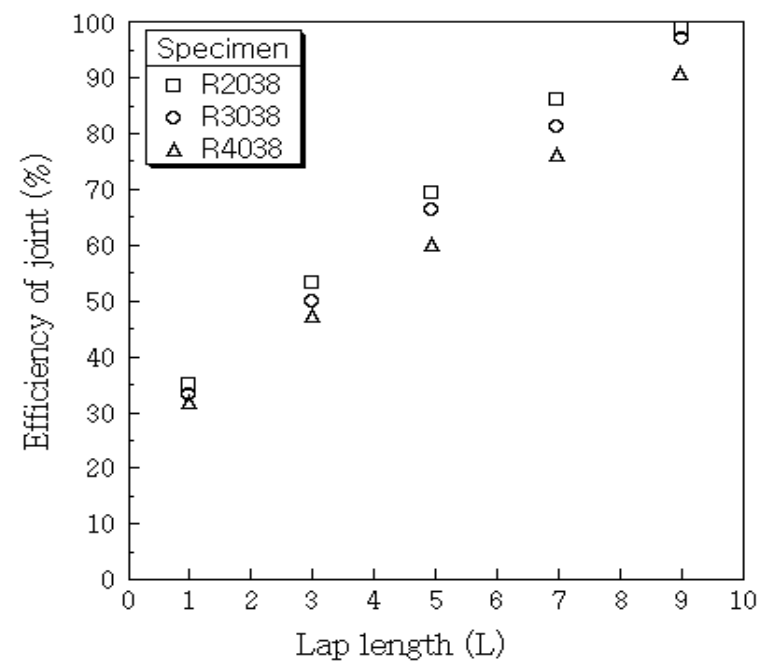

(a) Random GMT-sheet

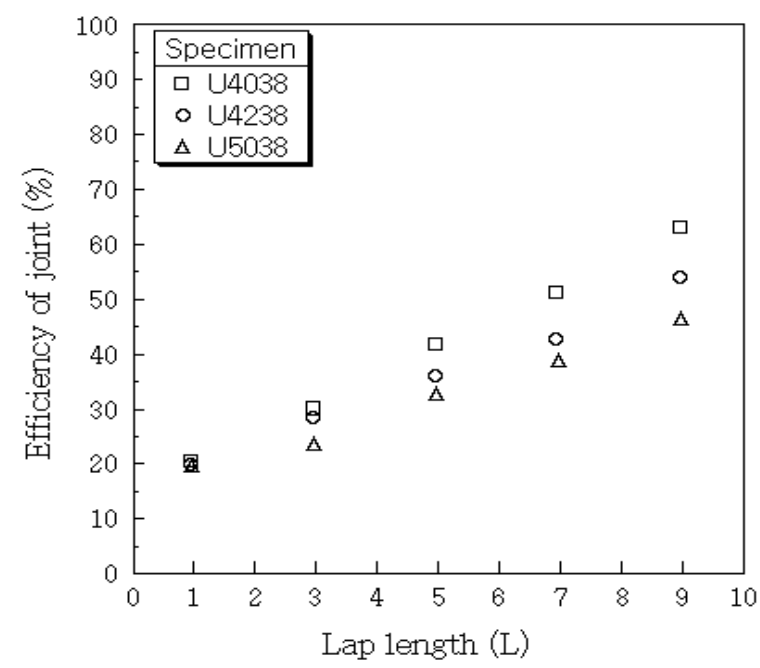

(b) Unidirectional GMT-sheet

Fig. 10 Effects of joining efficiency on the lap length $L$ 
glass fiber is not adhered each other but polypropylene is reinforcing, the role of adhesive material, strength, and joining connection efficiency of molding products is increased in linear fashion according to the increase of unit area.

Fig. 10 shows the lap joining connection efficiency according to the changes of lap length by testing tensile after lap joining molding in the condition that compression ratio $\left(R_{c r}\right)$ is set at 0 . By compared values of strength of molding material obtained by testing tensile only after high temperature compression press molding in a state of non overlapping of GMT-sheet and values of strength of joining materials obtained by lap joining molding, and joining connection efficiency according to lap length was compared. Lap joining efficiency was increased as lap length $L$ was increased in Fig. 10(a) and (b). As shown in Fig. 10(a), lap joining connection efficiency of randomly oriented composite R2038, R3038, and R4038 appeared almost similar and in Fig. 10(b), joining connection efficiency of unidirectional oriented composite U4038, U4238, and U5038 was reduced as fiber content ratio was higher. As shown in Fig. 10(b), as fiber content ratio was lower, joining efficiency appeared higher as melting fusion of matrix that played the role of adhesive materials was good and randomly oriented composite showed higher lap joining connection efficiency than unidirectional oriented composites.

Because fiber of randomly oriented composite is flown in the direction of length during molding but fiber of unidirectional oriented composites is sheared a lot in addition to becoming separation of only resins of matrix by the fluidity due to high compression pressure of press without orientation of fiber as fiber is layed in the direction of fluidity. Strength and joining connection efficiency of molding products were increasing according to the increase of lap length. Because glass fiber as reinforcement is not melted during lap joining molding and glass fiber is not adhered each other, but polypropylene is reinforcing, the role of adhesive material, strength, and joining connection efficiency of molding products is increased in linear fashion according to the increase of unit area.

\section{Conslusions}

The conclusions are following after studying strength and efficiency during lap joining molding of GMT-sheet.

(1) In high temperature \& compression press molding of GMT-sheet, compression load and degree of heterogeneity was increased as compression ratio was increased and also in case compression speed was increased, compression load was increased.

(2) In press lap joining molding of GMT-sheet, tensile stress and lap joining connection efficiency was increased according to the increase of lap length $L$. However, as the increase of compression ratio and fiber content ratio per unit area was higher in tensile test, it has caused the deterioration of lap joining efficiency after joining molding of GMT-sheet.

(3) Since fiber of randomly oriented composite of GMT-sheet was oriented into fluidity direction, it was advantageous in the aspect of lap joining efficiency but unidirectional oriented composite was not oriented and glass fibers was sheared and have caused the reduction of strength of unidirectional oriented composite. Therefore, from the viewpoint of recycling, randomly oriented composite GMT-sheet is more desirable than unidirectional oriented composite.

\section{ACKNOWLEDGMENT}

This study was supported by research fund from Chosun University, 2012

\section{REFERENCES}

(1) Kim, J. W., and Lee, D. G., 2011, "Creep and Tensile Properties of Press Molding Joined GMT-sheets," Transactions of Nonferrous Metals Society of China, Vol. 21, No. 1, pp. s170 $\sim$ s174.

(2) Lee, D. G., Sim, J. K., and Kim, J. W., 2006, "Study on the Fiber Orientation and Fiber Content Ratio Distribution during the Injection Molding for FRP," Journal of the KSMTE, Vol. 15, No. 4, pp. 1 7.

(3) Kim, J. W., Lee J. J., and Lee, D. G., 2008, "Measurement of Fiber Orientation Angle in FRP by Intensity Method," Journal of Materials Processing Technology, Vol. 201, No. 1-3, pp. 755 760.

(4) Lee, D. G., Sim, J. K., and Kim, J. W., 2005, "Fiber Orientation Distribution of Injection Molded Product on the FiberReinforced Polymeric Composites," Journal of the KSMTE, Vol. 14, No. 1, pp. 73 80.

(5) Kim, J. W., and Lee, D. G., 2010, "Effect of Fiber Orientation and Fiber Contents on the Tensile Strength in Fiber-reinforced Composites," Journal of Nanoscience and Nanotechnology, Vol. 10, No. 5, pp. 3650 3654.

(6) Kim, J. W., Kim, H. S., and Lee, D. G., 2011, "Study on Fibre Orientation of Weld Line Parts during Injection Moulding of Fiber Reinforced Plastic by Image Processing," Materials Research Innovations, Vol. 15, No. 1, pp. 303 306.

(7) Kim, J. W., Kim H. S., and Lee, D. G., 2012, "Effect of Molding Condition on Arithmetical Average Roughness of GMT-sheet Moldings," Advanced Science Letters, Vol. 8, pp. 682 686.

(8) Yaguchi, H., Hojo, H., Lee, D. G., and Kim, E. G., 1995, "Measurement of Planar Orientation of Fibers for Reinforced Thermoplastics Using Image Processing," International Polymer Processing, Vol. 10, No. 3, pp. 262 269. 